\title{
A Critical Role for Nucleus Accumbens Dopamine in Partner-Preference Formation in Male Prairie Voles
}

\author{
Brandon J. Aragona, Yan Liu, J. Thomas Curtis, Friedrich K. Stephan, and Zuoxin Wang \\ Department of Psychology and Program in Neuroscience, Florida State University, Tallahassee, Florida 32306-1270
}

\begin{abstract}
Although the role of nucleus accumbens (NAcc) dopamine (DA) in reward learning has been extensively studied, few investigations have addressed its involvement in learning socially relevant information. Here, we have examined the involvement of NAcc DA in social attachment of the "monogamous" prairie vole (Microtus orchrogaster). We first demonstrated that DA is necessary for the formation of social attachment in male prairie voles, because administration of haloperidol blocked, whereas apomorphine induced, partnerpreference formation. We then provided the first descriptions of DA neuroanatomy and tissue content in vole NAcc, and mating appeared to induce a 33\% increase in DA turnover. We also showed that administration of haloperidol directly into the NAcc blocked partner preferences induced by mating and apomorphine. In addition, administration of apomorphine into the NAcc but not the caudate putamen induced partner preferences in the absence of mating. Together, our data support the hypothesis that NAcc DA is critical for pair-bond formation in male prairie voles.
\end{abstract}

Key words: dopamine; nucleus accumbens; pair bonding; apomorphine; haloperidol; tyrosine hydroxylase; dopamine transporter; mating

\section{Introduction}

Perhaps the most important form of associative learning to humans is the formation of social attachments. Although considerable work has been done on dopamine (DA) involvement in associative learning, few studies have examined the formation of socially relevant associations. This is a concern because DA systems have been implicated in disorders associated with the inability to form social attachments (Mikkelsen et al., 1981; Schneier et al., 2000; Volkmar, 2001). In addition, previous work on associative learning has primarily used traditional laboratory rats that do not form strong social bonds, making it difficult to establish an animal model for disorders associated with social behavior. Recently, however, significant progress toward understanding the neurobiology of social attachment has been made using the "monogamous" prairie vole (Microtus ochrogaster) (Young et al., 1998; Insel and Young, 2001).

Prairie voles display a suite of behaviors characteristic of monogamy: preferential mating with one partner, remaining together during gestation, and biparental care throughout lactation (McGuire and Novak, 1984; Oliveras and Novak, 1986; Dewsbury, 1987; Carter and Getz, 1993; Getz and Carter, 1996). Most importantly, prairie voles form long-term pair bonds (Getz and Hofmann, 1986) that can be studied in the laboratory using a partner-preference test (Williams et al., 1992; Winslow et al., 1993; Insel et al., 1995). Prairie voles that mate repeatedly over 24 $\mathrm{hr}$ exhibit a strong preference for their partner versus a conspe-

\footnotetext{
Received 0ct. 11, 2002; revised Jan. 22, 2003; accepted Jan. 29, 2003

This work was supported by National Institutes of Health Grants MH-67396 to B.J.A., HD-40722 to J.T.C., and MH-58616 and MH-66734 to Z.X.W. We thank Christie D. Fowler and Jennifer R. Stowe for critical reading of this manuscript and Y. Joy Yu for technical assistance. We also thank Dr. Michael Kuhar of Emory University for providing the DAT antibody.

Correspondence should be addressed to Brandon J. Aragona, Department of Psychology, Florida State University, Tallahassee, FL 32306-1270. E-mail: aragona@psy.fsu.edu.

Copyright $\odot 2003$ Society for Neuroscience $\quad 0270-6474 / 03 / 233483-08 \$ 15.00 / 0$
}

cific stranger, whereas those paired for $6 \mathrm{hr}$ without mating do not. This behavioral paradigm has been used to examine neuronal and hormonal mechanisms underlying social attachment. Vasopressin (Winslow et al., 1993; Cho et al., 1999; Liu et al., 2001), oxytocin (Williams et al., 1994; Insel and Hulihan, 1995), and glucocorticoids (DeVries et al., 1995, 1996) have been implicated in the regulation of partner preferences. Importantly, these studies have demonstrated that sex-specific mechanisms may underlie social attachment in voles.

Mating-induced partner preferences likely involve reinforcing properties associated with mating along with approach behavior oriented toward the partner. Therefore, partner-preference formation can be viewed as a natural example of reward learning, a process that has significant DA involvement (Robbins and Everitt, 1996; Wise, 1996; Berridge and Robinson, 1998; Di Chiara, 1999; Ikemoto and Panksepp, 1999). Recently, DA has been shown to be involved in partner-preference formation in female prairie voles (Wang et al., 1999; Gingrich et al., 2000); however, nothing is known about the role of DA in males that also display mating-induced partner preferences. Given the tendency for prairie voles to show sexual dimorphism, it is of interest to examine the role of DA in pair bonding in males. We therefore conducted a series of experiments to assess the relationship between DA and partner-preference formation in male prairie voles. We also provide the first description of DA neuroanatomy and content in the prairie vole nucleus accumbens (NAcc) and assess how mating may alter DA turnover. Finally, we examined the role of NAcc DA in partner preferences by testing the effects of sitespecific administration of DA drugs in the NAcc on partnerpreference formation.

\section{Materials and Methods}

Subjects. Subjects were sexually naive male prairie voles from a laboratory breeding colony. At $\sim 21 \mathrm{~d}$ of age, subjects were weaned and housed in same-sex sibling pairs in plastic cages $(20 \times 50 \times 40 \mathrm{~cm})$. Water and food 
were provided ad libitum, a 14/10 hr light/dark cycle was maintained, and the temperature was $\sim 20^{\circ} \mathrm{C}$. All subjects were between $80-120 \mathrm{~d}$ of age when tested and weighed between 40-50 gm. Ovariectomized (OVX) females served as stimulus animals. For manipulations that required mating ( $24 \mathrm{hr}$ pairings), females were estrogen primed with subcutaneous estrodial benzoate (EB) pellets implanted $4 \mathrm{~d}$ before pairing (Smith et al., 2001). Partner and stranger females received EB pellets on the same day. All behavioral interactions during $24 \mathrm{hr}$ of pairing were videotaped for detailed behavioral analysis.

Partner preference test. The testing apparatus consisted of a central cage $(20 \times 25 \times 45 \mathrm{~cm})$ joined by hollow tubes $(7.5 \times 16 \mathrm{~cm})$ with two parallel identical cages, each housing a stimulus animal (Curtis et al., 2001; Liu et al., 2001). The subjects were free to move throughout the apparatus, whereas stimulus animals were loosely tethered within their separate cages and had no direct contact with each other. The familiar partner (housed with the subject before the partner-preference test) and an unfamiliar conspecific stranger (a female that had not previously encountered the subject) were used as stimulus animals. Behavior was recorded during the $3 \mathrm{hr}$ test using a time-lapse video recording system (12:1 compression, Panasonic recorder; Panasonic, Secaucus, NJ). Motion sensors automatically recorded the time subjects spent in each cage as well as the number of cage entries, and these data were immediately transferred to a computer for statistical analysis. Experimenters who were blind to the manipulation reviewed videotaped behaviors and recorded side-by-side contact within each treatment. Differences were analyzed with a paired samples $t$ test. A partner preference was defined as significantly greater mean contact time with the partner compared with the stranger. Because the effect of DAergic drugs on partner-preference formation could be secondary to their effects on locomotor activity, we also examined the frequency of total cage entries during the partnerpreference test using a one-way ANOVA. For subjects that had received cannulation surgery, the number of cage crossings during the cohabitation period was recorded and compared between treatment groups with a one-way ANOVA. Because partner preferences are induced by mating during the initial $24 \mathrm{hr}$ cohabitation, the number of mating bouts that occurred during the first $6 \mathrm{hr}$ was recorded and compared between treatment groups with a one-way ANOVA to assess whether DAergic drugs effected mating behavior.

Perfusion and immunocytochemistry. Animals were anesthetized with sodium pentobarbital (1 mg per 10 gm body weight) and perfused transcardially with $0.9 \%$ saline followed by $4 \%$ paraformaldehyde in $0.1 \mathrm{M}$ $\mathrm{PBS}, \mathrm{pH} 7.6$, at $4^{\circ} \mathrm{C}$. Brains were postfixed for $30 \mathrm{~min}$ in the same fixative and then immersed in $30 \%$ sucrose in PBS. For immunocytochemistry, a set of $30 \mu \mathrm{m}$ coronal sections that spanned the NAcc at $90 \mu \mathrm{m}$ intervals was rinsed in $0.1 \mathrm{M}$ PBS, $\mathrm{pH} 7.4$, treated with $0.3 \%$ hydrogen peroxide in PBS, incubated in a blocking solution [PBS with $0.3 \%$ Triton X-100 (PBT), 10\% normal goat serum (NGS), and $2 \%$ bovine albumin (BSA)] for $1 \mathrm{hr}$, and then incubated in 1:30,000 rabbit anti-dopamine transporter (anti-DAT) polyclonal antibody (a gift from Dr. Michael Kuhar, Emory University, Atlanta, GA) in PBT with $2 \%$ NGS and $2 \%$ BSA at $4{ }^{\circ} \mathrm{C}$ for $48 \mathrm{hr}$. After incubation with 1:300 biotinylated goat anti-rabbit antibody (Vector Laboratories, Burlingame, CA) in PBT with 2\% NGS and $2 \% \mathrm{BSA}$ at room temperature for $2 \mathrm{hr}$, sections were rinsed, incubated with $\mathrm{ABC}$ complex (Vector Laboratories) for $1.5 \mathrm{hr}$, and then stained using 3-3' -diaminobenzidine (DAB kit; Vector Laboratories). A similar staining method was used on an alternate set of brain sections for tyrosine hydroxylase (TH) immunocytochemistry with rabbit antityrosine hydroxylase polyclonal antibody as a primary antibody (1:8000; Chemicon, Temecula, CA).

Tissue microdissection. Subjects were killed via rapid decapitation, and brains were immediately extracted and frozen. Coronal sections $(300 \mu \mathrm{m})$ were cut on a cryostat and frost mounted onto microscope slides. Bilateral tissue punches with a $1 \mathrm{~mm}$ diameter were taken from the NAcc, caudate putamen (CP), and paraventricular nucleus of the hypothalamus (PVN) (areas that showed high-density TH staining) and stored at $-80^{\circ} \mathrm{C}$ until analyzed. Neurochemical extraction was performed as described previously (Aragona et al., 2002), except that tissue samples were sonicated (model 60; Fisher Scientific, Houston, $\mathrm{TX}$ ) in $75 \mu \mathrm{l}$ of $0.1 \mathrm{~m}$ perchloric acid (PCA) (Fisher Scientific) with
$0.02 \%$ EDTA (Fisher Scientific). Samples were assayed for DA, the DA metabolites dihydroxyphenylacetic acid (DOPAC) and homovanillic acid (HVA), norepinephrine (NE), serotonin (5-HT), and the 5-HT metabolite 5-hydroxyindoleacetic acid (5-HIAA). Means for each neurochemical as well as the DOPAC to DA ratio (index of DA turnover) between treatment groups were compared using a one-way ANOVA.

HPLC with electrochemical detection. Peak separation was achieved using a microdialysis MD-150 analytical column (ESA, Chelmsford, MA). The mobile phase consisted of $75 \mathrm{~mm}$ sodium dihydrogen phosphate monohydrate (Electron Microscopy Sciences, Fort Washington, PA), $1.7 \mathrm{~mm} 1$-octanesulfonic acid sodium salt, $0.01 \%$ triethylamine (Aldrich, Milwaukee, WI), $25 \mu \mathrm{m}$ EDTA (Fisher Scientific), and 10\% acetonitrile (Electron Microscopy Sciences), and the $\mathrm{pH}$ was adjusted to 3.85 with $85 \%$ phosphoric acid (Fisher Scientific). Samples were first oxidized at $250 \mathrm{mV}$ and then reduced at $-250 \mathrm{mV}$. The flow rate was $0.7 \mathrm{ml} / \mathrm{min}$. Standards were diluted in $0.1 \mathrm{~m}$ PCA $(0.02 \%$ EDTA) and used to construct a standard curve. The peak area was calculated using Millennium software (Waters Associates, Milford, MA), and standard curves were then used to convert peak area units into the total amount. The limit of detection was $\sim 5$ pg per sample.

Stereotaxic cannulation and injection. Subjects were anesthetized with sodium pentobarbital ( $2.5 \mathrm{mg}$ per $40 \mathrm{gm}$ body weight), and 26 gauge bilateral guide cannulas (Plastics One, Roanoke, VA) aimed at the NAcc were implanted stereotaxically (nose bar, $-2.5 \mathrm{~mm} ; 1.7 \mathrm{~mm}$ rostral, \pm 1 $\mathrm{mm}$ bilateral, $4.5 \mathrm{~mm}$ ventral to bregma). Control injections were aimed at the $\mathrm{CP}$ (nose bar, $-2.5 \mathrm{~mm} ; 1.7 \mathrm{~mm}$ rostral, $\pm 1 \mathrm{~mm}$ bilateral, $2.5 \mathrm{~mm}$ ventral to bregma). After 3-5 d of recovery, subjects received microinjections (200 $\mathrm{nl}$ per side) of either CSF or CSF containing haloperidol (Halo) or apomorphine (Apo) (Research Biochemicals, Natick, MA). The procedure for dissolving haloperidol and apomorphine was performed in the same manner as in a previous study (Wang et al., 1999). Drugs were always mixed fresh before administration. Because neither compound is easily dissolved in physiological saline (or CSF) and may have been suspended in the vehicle, the drug vial was shaken well before administration. Injections were made with a 33 gauge needle that extended $1 \mathrm{~mm}$ below the guide cannula into the target area. The needle was connected to a Hamilton syringe (Hamilton, Reno, NV) through polyethylene-20 tubing. Plunger depression was performed slowly, requiring $10-15 \mathrm{sec}$ per injection. After behavioral testing, subjects were killed, and an observer who was blind to experimental conditions verified injection sites histologically. Subjects with misplaced cannulas were excluded from data analysis.

\section{Results}

Experiment 1a: does peripheral administration of the dopamine antagonist haloperidol block mating-induced partner preferences?

Sexually naive males were randomly assigned into one of three groups that received intraperitoneal injections of either $200 \mu \mathrm{l}$ of saline $(n=8)$ or saline containing $0.4 \mu \mathrm{g}(n=10)$ or $4 \mu \mathrm{g}(n=8)$ of the nonselective DA antagonist haloperidol. Subjects were then immediately paired with EB-primed OVX females and allowed to mate ad libitum for $24 \mathrm{hr}$. Behavior was videotaped, and the effect of haloperidol on mating was assessed. Males that did not mate within the first $6 \mathrm{hr}$ were excluded from the experiment. After $24 \mathrm{hr}$ of mating, subjects were tested for partner preferences.

As expected, saline-injected control subjects formed partner preferences with their respective mates after $24 \mathrm{hr}$ of mating ( $p=$ 0.05 ) (Fig. 1A). However, both doses of haloperidol blocked mating-induced partner preferences $(0.4 \mu \mathrm{g}, p=0.33 ; 4.0 \mu \mathrm{g}$, $p=0.78$ ) (Fig. $1 A$ ). Although haloperidol blocked partner preferences, it did not affect the number of mating bouts during the initial cohabitation period (control, $6.9 \pm 1.5 ; 0.4 \mu \mathrm{g}$ of Halo, $7.2 \pm 3.0 ; 4 \mu \mathrm{g}$ of Halo, $6.4 \pm 2.7$ ) or locomotor activity measured by cage entries during the partner-preference test (control, 
A

70

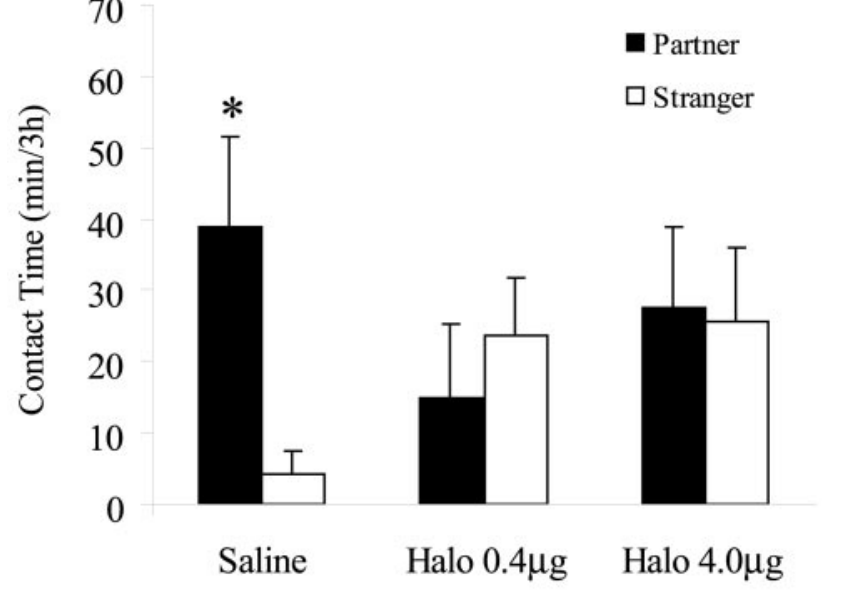

B

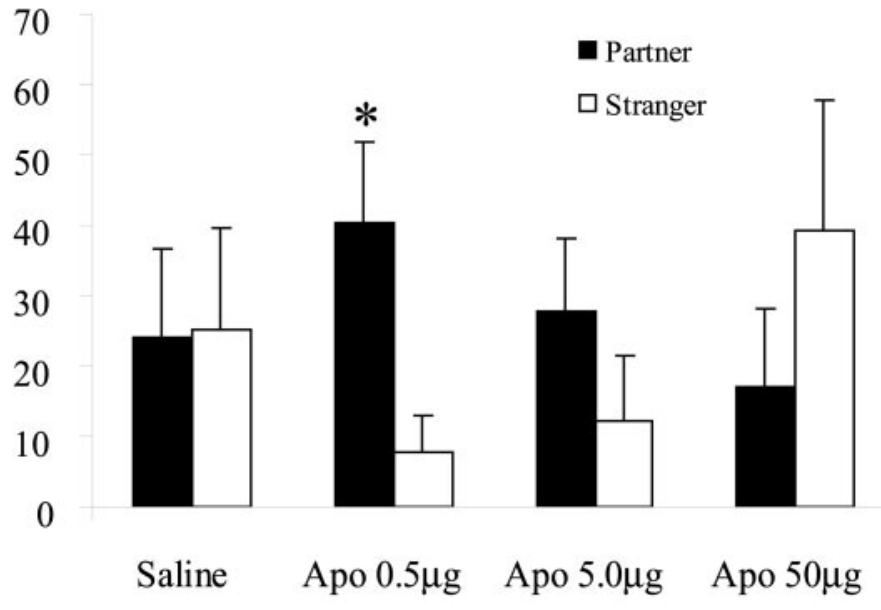

Figure 1. Peripheral administration of dopamine drugs influenced partner preferences in male prairie voles. $A$, Males injected intraperitoneally with saline and mated with a partner for 24 hr had more side-by-side contact with the partner versus a conspecific stranger. This partner preference was not seen in males receiving saline injections containing the dopamine antagonist $H a l 0$. $B$, Males injected with saline and paired with a partner for $6 \mathrm{hr}$ in the absence of mating showed nonselective side-by-side contact during the partner-preference test. However, males receiving the low ( 0.5 $\mu \mathrm{g}$ ) but not the high $(5$ and $50 \mu \mathrm{g})$ dose of the dopamine agonist Apo had more contact with the partner versus a stranger. ${ }^{*} p<0.05$; paired samples $t$ test. Error bars indicate SEM.

$105.7 \pm 17.5 ; 0.4 \mu \mathrm{g}$ of Halo, $67.5 \pm 14.1 ; 4 \mu \mathrm{g}$ of Halo, $97.64 \pm$ 10.4). Therefore, haloperidol blockade of DA receptors prevented the formation of a partner preference without disruption of mating.

Experiment 1b: does peripheral administration of the dopamine agonist apomorphine induce partner preferences in the absence of mating?

Sexually naive males were divided into four groups that received intraperitoneal injections of either $200 \mu$ l of saline $(n=8)$ or saline containing $0.5 \mu \mathrm{g}(n=9), 5 \mu \mathrm{g}(n=10)$, or $50 \mu \mathrm{g}(n=8)$ of apomorphine. Immediately after injection, subjects were paired with OVX females that were not treated with estradiol for $6 \mathrm{hr}$ of cohabitation in the absence of mating. Thereafter, subjects were tested for partner preferences. All behavior was videotaped and reviewed, and the absence of mating was confirmed.

Subjects that received saline injections before $6 \mathrm{hr}$ of cohabitation showed nonselective side-by-side contact during the partner-preference test $(p=0.96)$ (Fig. $1 B$ ). However, those that received low-dose intraperitoneal administration of apomorphine $(0.5 \mu \mathrm{g})$ showed partner preferences $(p<0.05)$ (Fig. $1 B)$. Subjects given higher doses of apomorphine $(5$ and $50 \mu \mathrm{g})$ did not show partner-preference formation $(p=0.35$ and 0.39 , respectively). Locomotor activity during the partner-preference test was not different between the four groups (control, 82.1 \pm 11.5; $0.5 \mu \mathrm{g}$ of Apo, $101.8 \pm 39.4 ; 5 \mu \mathrm{g}$ of Apo, $118.2 \pm 20.6 ; 50$ $\mu \mathrm{g}$ of Apo, $117.8 \pm 31.5$.)

\section{Experiment 2: what is the dopamine innervation in nucleus} accumbens of male prairie voles?

Experiment 1 showed that DA is involved in partner-preference formation in male prairie voles. Previous experiments with females have also shown that DA, and specifically NAcc DA, is important for partner-preference formation (Gingrich et al., 2000). However, DA neuroanatomy of the prairie vole NAcc has never been described. In this experiment, sexually naive adult male prairie voles were prepared for immunocytochemistry. DA innervation of the NAcc was observed by immunocytochemically labeling for tyrosine hydroxylase (the rate-limiting enzyme for the production of DA) and for DAT.

Figure 2 shows matched sections of TH and DAT labeling in the NAcc and several other brain areas of male prairie voles. Light microscopic analysis revealed similar patterns of staining for both TH and DAT in the NAcc, CP, and olfactory tubercle (OT). The massive TH and DAT staining in these areas indicates dense DAterminal innervation. For TH, staining appears extremely dense in the NAcc, CP, and OT. DAT is most densely stained in the CP and OT, with lighter staining in the medial portion of the NAcc, especially in the more caudal sections. Inspection of subcommissural regions of the ventral forebrain reveals that the ventral pallidum (VP) has only moderate labeling (Fig. 2C,D); however, fibers are clearly visible at higher magnification.

Experiment 3: does mating increase dopamine turnover in nucleus accumbens of male prairie voles?

Sexually naive males were paired either with a male sibling (control, $n=8$ ), an EB-primed OVX female with which the subject chose not to mate (nonmated, $n=8$ ), or an EB-primed OVX female with which the subject mated (mated, $n=12$ ). Subjects in the mated group were killed 30 min after mating onset and averaged $40 \mathrm{~min}$ total time together. Therefore, control and nonmated groups were paired for $40 \mathrm{~min}$ and then killed. Bilateral tissue punches were taken from the NAcc, CP, and PVN (Fig. 3A), and tissue samples were assayed for several neurochemicals.

In the NAcc, mated males had 33\% higher mean values of DA turnover compared with control and nonmated subjects, but this increase was not statistically significant $(p=0.17)$ (Fig. $3 B)$. A similar trend was also found in the CP but not in the PVN (Fig. $3 B$ ). Figure $3 C$ shows that under baseline conditions, DA turnover in the NAcc was approximately two times greater than in the $\mathrm{CP}$, whereas the CP had approximately three times the amount of DA compared with the NAcc. The PVN contained much less DA compared with the NAcc and CP. The PVN was primarily noradrenergic and also had approximately two times the 5-HT com- 
pared with the NAcc and CP. Mating and social experience had no significant effects on any of the other neurochemicals measured.

\section{Experiment 4a: does site-specific administration of the dopamine antagonist haloperidol into nucleus accumbens block mating-induced partner preferences?}

Sexually naive males were implanted with guide cannulas bilaterally aimed at the NAcc. After 3-5d of recovery, subjects were divided into one of two groups that received microinjections of $200 \mathrm{nl}$ of CSF alone per side $(n=5)$ or CSF with 4 ng of haloperidol $(n=7)$. Subjects were then paired with an EB-primed OVX female for $24 \mathrm{hr}$ of mating and then tested for partner preferences. All behavior was videotaped and analyzed as in experiment la.

As expected, the control group displayed significant partner-preference formation $(p<0.05)$, and haloperidol treatment completely blocked mating-induced partner preferences $(p=1)$ (Fig. $4 A$ ). This effect was not caused by disruption of mating during the first $6 \mathrm{hr}$ of the cohabitation period. Rather, haloperidoltreated subjects showed a trend for more mating bouts compared with control animals (control, $5.4 \pm 1 ; 4$ ng of Halo, $8.1 \pm 1.4 ; p=0.1)$. Haloperidoltreated animals did not differ from controls in locomotor activity during the first $6 \mathrm{hr}$ of the cohabitation period (as measured by the number of times the subject crossed the center of the cage) or during the partnerpreference test.

\section{Experiment 4b: does site-specific administration of the dopamine agonist apomorphine into nucleus accumbens induce partner preferences in the absence of mating?} Sexually naive males were cannulated, as described in experiment $4 \mathrm{a}$, and divided into one of four groups that received microinjections of either CSF alone ( $200 \mathrm{nl}$ per side; $n=7$ ), CSF containing $0.04 \mathrm{ng}(n=8)$ or $4 \mathrm{ng}(n=7)$ of apomorphine, or CSF containing $0.04 \mathrm{ng}$ of apomorphine with $0.4 \mathrm{ng}$ of haloperidol $(n=8)$. To assess site specificity, a final group of subjects $(n=6)$ was implanted with guide cannulas aimed at the CP $(2 \mathrm{~mm}$ dorsal to NAcc) and received injections of CSF containing $0.04 \mathrm{ng}$ of apomorphine. All subjects were paired with OVX females that were not treated with estradiol for $6 \mathrm{hr}$ of cohabitation in the absence of mating and then immediately tested for partner preferences. Behavior was videotaped and analyzed as in experiment $1 \mathrm{~b}$.

Control subjects that received CSF injections into the NAcc before $6 \mathrm{hr}$ of cohabitation showed nonselective side-by-side contact during the partner-preference test $(p=0.7)$ (Fig. $4 B)$. However, similar to intraperitoneal administration, subjects that received administration of apomorphine at a low dose $(0.04 \mathrm{ng})$ but not a high dose $(4 \mathrm{ng})$ showed partner preferences $(p<0.01)$ (Fig. $4 B$ ). This apomorphine-induced partner preference was blocked by coadministration of $0.4 \mathrm{ng}$ of haloperidol $(p=0.74)$.
In addition, apomorphine failed to induce partner preferences when injected into the $\mathrm{CP}(p=0.93)$, suggesting that $\mathrm{DA}$ acts in a site-specific manner to influence partner preferences (Fig. $4 B$ ). Drug treatment did not affect locomotor activity during the partner-preference test; however, subjects receiving NAcc apomorphine showed decreased locomotor activity during the $6 \mathrm{hr}$ of cohabitation (as measured by the number of times the subject crossed the center of the cage) (control, 297.8 $\pm 79.5 ; 0.04 \mathrm{ng}$ of Apo, $135.1 \pm 14.7,4 \mathrm{ng}$ of Apo, $151.7 \pm 24.2 ; p=0.04$ ). Importantly, there were no differences in locomotor activity between the two apomorphine groups. Injection sites for apomorphine in the NAcc and CP are illustrated in Figure 5. All NAcc injections were located in the more rostral portions of the NAcc, where TH/DAT is most abundant.

\section{Discussion}

This study shows, for the first time, that DA is critically involved in social attachment in male prairie voles. Administration of the DA antagonist haloperidol blocked mating-induced partner preferences, whereas the DA agonist apomorphine induced this behavior in the absence of mating. This is also the first study to describe DA neuroanatomy, tissue content, and turnover in the vole NAcc. Although not statistically significant, mating appears to increase DA turnover in the NAcc by $33 \%$, suggesting that DA may be released during mating. The involvement of the NAcc in pair bonding was demonstrated by site-specific administration of haloperidol or apomorphine into the NAcc. Haloperidol blocked 
A

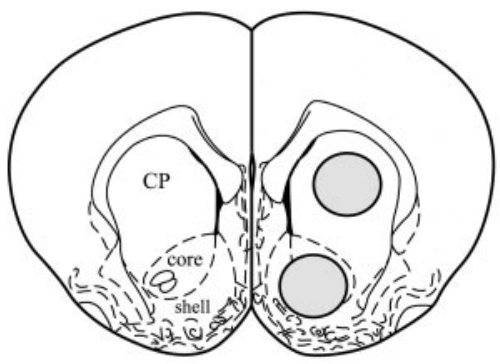

C

\begin{tabular}{l|lrrrrrr}
\hline & & DA & DOPAC & HVA & NE & 5-HT & 5-HIAA \\
\hline \multirow{4}{*}{ NAcc } & Control & $118.9 \pm 10.1$ & $22.0 \pm 2.0$ & $23.1 \pm 1.9$ & $6.9 \pm 1.0$ & $9.5 \pm 1.3$ & $1.3 \pm 0.3$ \\
& Non-Mated & $125.4 \pm 19.7$ & $23.5 \pm 2.2$ & $21.7 \pm 2.3$ & $10.8 \pm 1.7$ & $10.3 \pm 1.1$ & $1.2 \pm 0.3$ \\
& Mated & $106.7 \pm 7.5$ & $29.4 \pm 4.6$ & $22.8 \pm 1.7$ & $9.5 \pm 2.0$ & $9.8 \pm 1.0$ & $1.5 \pm 0.2$ \\
& & & & & & & \\
$\mathrm{CP}$ & Control & $339.2 \pm 18.4$ & $37.0 \pm 4.8$ & $37.2 \pm 3.3$ & $5.7 \pm 0.9$ & $11.7 \pm 0.6$ & $0.9 \pm 0.1$ \\
& Non-Mated & $304.1 \pm 15.7$ & $35.3 \pm 2.8$ & $30.2 \pm 1.4$ & $5.5 \pm 0.8$ & $10.9 \pm 0.7$ & $1.0 \pm 0.1$ \\
& Mated & $322.6 \pm 25.0$ & $42.8 \pm 4.3$ & $33.6 \pm 1.9$ & $5.2 \pm 0.5$ & $11.0 \pm 0.9$ & $1.1 \pm 0.2$ \\
& & & & & & & \\
PVN & Control & $12.8 \pm 0.8$ & $2.1 \pm 0.2$ & $7.3 \pm 0.6$ & $69.1 \pm 5.4$ & $21.0 \pm 4.1$ & $2.1 \pm 0.6$ \\
& Non-Mated & $13.5 \pm 0.9$ & $2.3 \pm 0.1$ & $6.5 \pm 0.2$ & $87.5 \pm 7.0$ & $18.7 \pm 1.0$ & $2.0 \pm 0.2$ \\
& Mated & $13.9 \pm 0.7$ & $2.3 \pm 0.3$ & $6.4 \pm 0.5$ & $79.0 \pm 4.3$ & $18.1 \pm 1.5$ & $2.2 \pm 0.2$ \\
\hline
\end{tabular}

Figure 3. Effect of mating on dopamine turnover and neurochemical content in the male prairie vole brain. $A$, Schematic illustration of tissue-punch location for NAcc and CP. The illustration is from the atlas of Paxinos and Watson (1986), plate 11. B, Mean dopamine turnover from the NAcc, CP, and PVN for male prairie voles paired with same-sex siblings (white bars), a novel female (gray bars), or a novel female with mating (black bars). Mated males showed a 33\% increase in dopamine turnover in the NAcc compared with control and nonmated males; however, this difference was not statistically significant. A similar pattern of increase is seen in the CP but not the PVN. Error bars indicate SEM. C, Table showing mean content (picograms per microgram of protein \pm SEM) of DA, DOPAC, HVA, NE, 5-HT, and 5-HIAA in the NACC.

partner preferences induced either by mating or by apomorphine. Similar to intraperitoneal administration, apomorphine in the NAcc induced partner-preference formation in the absence of mating at low but not high doses. Together, these data suggest that mating induces DA release in NAcc, and that released DA is necessary for pair-bond formation of male prairie voles.

\section{DA is involved in partner-preference formation}

DA receptor antagonism by peripheral haloperidol administration blocked mating-induced partner preferences. Importantly, haloperidol did not disrupt mating or locomotor activity, and therefore, its effect on partner-preference formation was not secondary to effects on mating or locomotion. These data suggest that haloperidol affected a social consequence of mating and demonstrate that access to DA receptors is necessary for partnerpreference formation in male prairie voles.

Peripheral administration of apomorphine at a low dose induced partner-preference formation in the absence of mating, providing additional evidence that DA is involved in pair-bond formation in male prairie voles. However, in a previous study, administration of apomorphine at a high dose (e.g., $50 \mu \mathrm{g})$ induced partner preferences in females (Wang et al., 1999). Interestingly, males in this study that were given the same dose of apomorphine appeared to spend more time with the stranger. This avoidance of the partner is comparable with male rats that show conditioned taste aversion when given a similar dose of apomorphine (Wang et al., 1997). Although there appear to be differences in sensitivity to DA between males and females, more dramatic sex differences have been reported for vasopressin, oxy- tocin, and corticosterone. It has been reported that vasopressin and increases in corticosterone are more important for male pair bonding (Winslow et al., 1993; DeVries et al., 1996), whereas oxytocin and decreases in corticosterone are more important for female pair bonding (DeVries et al., 1995; Insel and Hulihan, 1995). Although a recent study indicated that sex differences in the effects of vasopressin and oxytocin on pair bonding are less dramatic, male voles showed a greater sensitivity to neuropeptide manipulation (Cho et al., 1999).

\section{Neuroanatomical and neurochemical description of vole NAcc}

The NAcc and VP have been implicated in social attachment (Gingrich et al., 2000; Pitkow et al., 2001; Young et al., 2001; Lim and Young, 2002; Liu and Wang, 2002). In this study, we performed TH and DAT immunocytochemistry to examine DA innervation in these and associated brain areas. Despite differences in social organization and behavior, prairie voles showed similar patterns of DA innervation compared with traditional lab rodents (Hokfelt et al., 1984; Voorn et al., 1986; Ciliax et al., 1995; Freed et al., 1995; Nirenberg et al., 1997; Jansson et al., 1999; Nobrega et al., 1999). These data suggest that the pattern of DA innervation in the NAcc does not correlate with social behavior. However, it is possible that monogamous and nonmonogamous voles have postsynaptic differences in DA neuroanatomy. This is certainly the case for oxytocin and vasopressin receptors (Insel and Shapiro, 1992; Insel et al., 1994). Therefore, additional experiments examining the distribution pattern of D1- and D2-type receptors in voles are necessary. However, it is also possible that prairie voles have similar DA systems compared with nonmonogamous rodents but differ in other neurotransmitter systems that interact with DA in the regulation of pair bonding. For example, access to both oxytocin and DA receptors in the NAcc is required for partner-preference formation in female prairie voles (Liu and Wang, 2002), and the NAcc of prairie but not nonmonogamous voles contains oxytocin receptors (Insel and Shapiro, 1992). Therefore, species differences in oxytocin or other neurotransmitter systems (i.e., vasopressin) (Lim and Young, 2002) that may interact with DA could play a critical role in the NAcc DA effects on pair bonding.

The DOPAC/DA ratio is commonly used as an index of DA turnover (Blackburn et al., 1989). Mated male voles showed greater mean levels of DA turnover primarily in the NAcc and to a lesser extent in the CP. Although neither difference reached statistical significance, these patterns of increase are consistent with data suggesting that mating induces DA release in the NAcc and CP in rats (Pfaus et al., 1990; Mas et al., 1995) and in female prairie voles (Gingrich et al., 2000; Curtis et al., 2003). Failure to detect significant group differences may have been attributable to the fact that the tissueextraction assay was not sensitive enough to detect more subtle changes, such as extracellular release. In addition, the optimal killing time after mating onset may not have been chosen. 
A

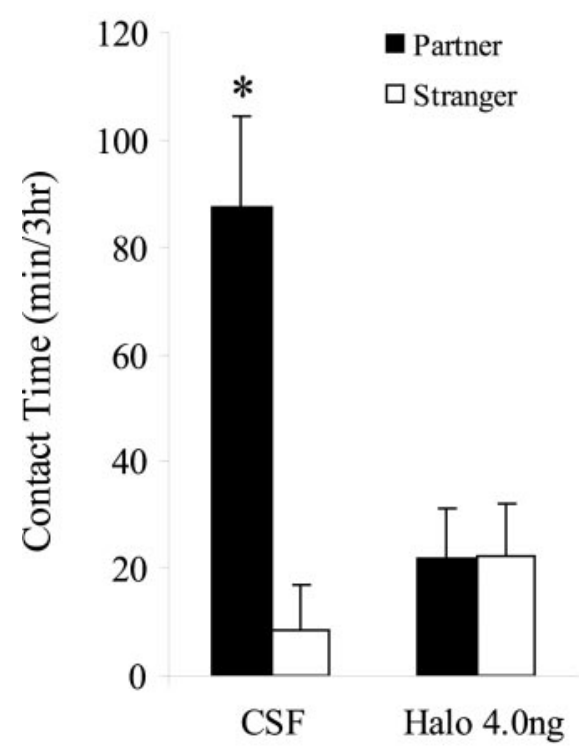

B

120

100

NAcc

80

60

40

20

0
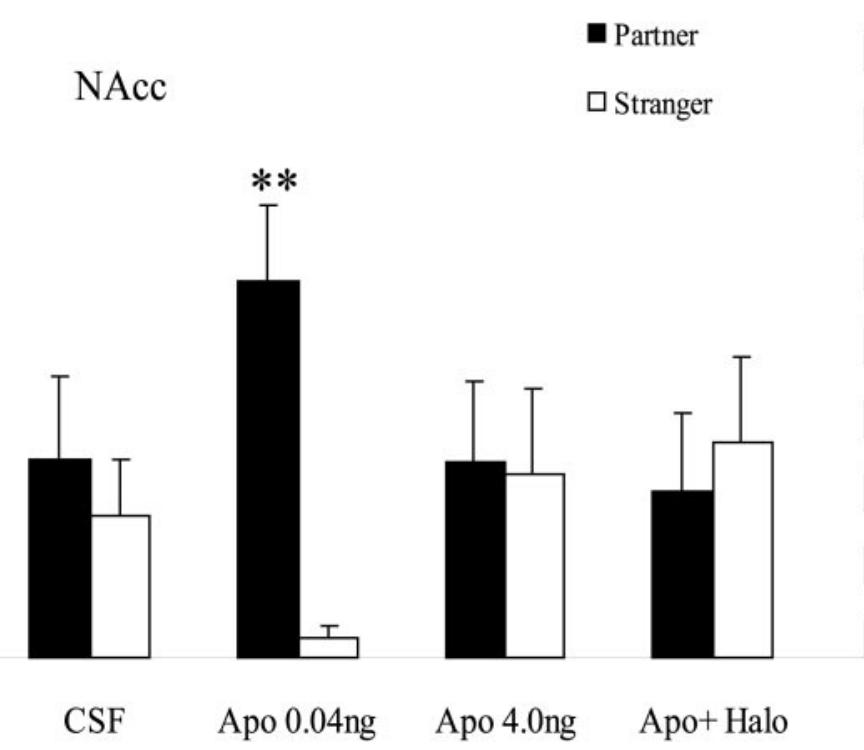

\section{$\mathrm{CP}$}

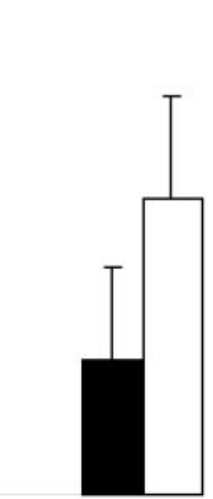

Apo 0.04ng

Figure 4. NAcc dopamine is involved in partner-preference formation of male prairie voles. $A$, Males microinjected with artificial CSF into the NAcc and mated with a partner for $24 \mathrm{hr}$ had more side-by-side contact with the partner versus a conspecific stranger. This mating-induced partner preference was blocked by NAcc administration of CSF containing Halo. $B$, Males microinjected with CSF and paired with a partner for $6 \mathrm{hr}$ in the absence of mating showed nonselective side-by-side contact with the partner or stranger. However, males receiving the low (0.04 ng) but not the high $(4 \mathrm{ng})$ dose of the dopamine agonist Apo displayed partner preferences. This apomorphine-induced $(0.04 \mathrm{ng})$ partner preference was blocked by coadministration of haloperidol ( $0.4 \mathrm{ng})$. In addition, apomorphine $(0.04 \mathrm{ng})$ failed to induce partner preferences when administered into the CP. ${ }^{*} p<0.05$ and ${ }^{* *} p<0.005$; paired samples $t$ test. Error bars indicate SEM.

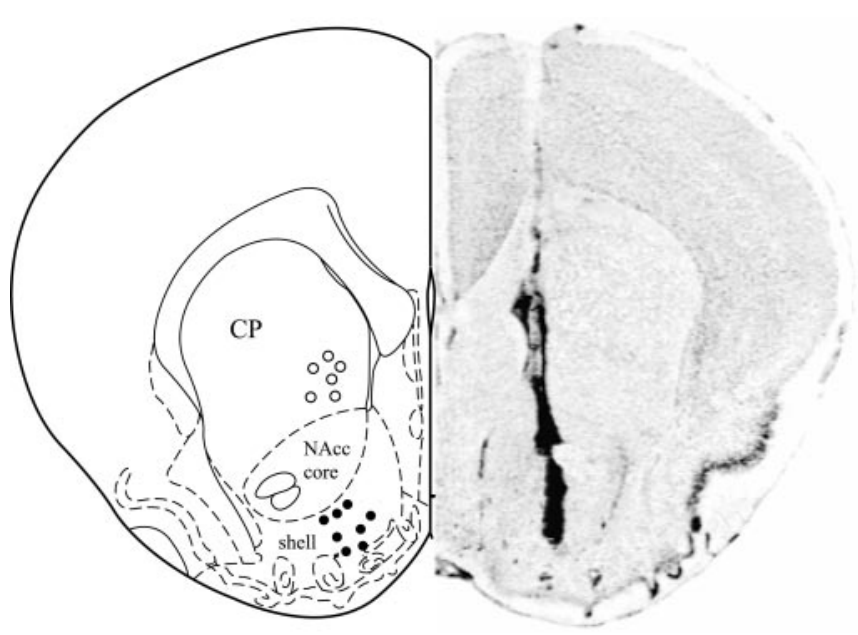

Figure 5. A schematic illustration (left) showing locations of microinjections of apomorphine into the $N A c c$ or $C P$, and a representative photomicrograph of vole brain section (right) displaying the site of microinjection into the NAcc.

\section{NAcc is important for DA regulation of partner-preference formation}

As with peripheral administration, haloperidol administered into the NAcc blocked mating-induced partner preferences without disrupting mating. In fact, subjects that received haloperidol directly into the NAcc showed a trend for increased mating behavior. This increase in mating is analogous to increases in free food consumption after haloperidol injection into the NAcc of rats (Salamone et al., 1991). This suggests that haloperidol may have altered the hedonic value of mating (but see Berridge and Robinson, 1998). Haloperidol in the NAcc also blocked agonistinduced partner preferences, and because adverse effects on mating or locomotor activity were not observed, this suggests that DA receptor blockade within the NAcc directly prevented partnerpreference formation.

Similar to peripheral administration, apomorphine injected directly into the NAcc induced partner preferences in the absence of mating at a low but not a high dose. A possible explanation for the apomorphine dose-response follows from the fact that apomorphine is a general DA agonist and has approximately three orders of magnitude greater binding affinity for D2-type compared with D1-type receptors (Missale et al., 1998). Therefore, apomorphine at low doses may primarily act on D2-type receptors to induce partner-preference formation. This is consistent with data from female prairie voles that use a D2-type receptormediated mechanism for partner-preference formation (Wang et al., 1999; Gingrich et al., 2000). Conversely, apomorphine at high doses may activate both D1- and D2-type receptors, and activation of D1-type receptors may prevent partner-preference formation. If true, D1-type receptors are not simply uninvolved, but when activated, antagonize the effects of D2-type receptors. This notion is supported by the fact that D1- and D2-type receptors have opposite intracellular-signaling effects (Missale et al., 1998), opposing control of cocaine-seeking behavior (Self et al., 1996), differential regulation over opioid-induced place conditioning (Shippenberg et al., 1993), and opposite influence over certain aspects of copulation (Hull et al., 1992).

Administration of low-dose apomorphine has also been reported to reduce locomotor activity (Van Ree and Wolterink, 1981), and this hypomotility is mediated in the NAcc (Radhakishun and Van Ree, 1987). This is supported by our data that show decreased locomotor activity induced by apomorphine injections into the NAcc. However, locomotor activity between the two apomorphine groups was nearly identical, suggesting that their differences in partner preferences cannot be attributed to locomotor activity. Therefore, apomorphine in the NAcc had similar behavioral consequences compared with rats, with re- 
spect to locomotor activity, but also had important social consequences for prairie voles.

Finally, these behavioral effects of apomorphine appear to be site-specific, because partner-preference formation occurred after injections into the NAcc but not the CP. These data, together with the data from female prairie voles (Gingrich et al., 2000), suggest that NAcc DA regulates partner-preference formation in prairie voles. The site specificity within the NAcc with respect to partner preferences is worth additional attention. There is a tremendous amount of literature showing significant differences between the two main components of the NAcc, the core and shell (Zahm, 2000). In this study, all apomorphine injections were administered into the NAcc shell. A potential core/shell distinction in the regulation of social attachment is currently being investigated in ongoing experiments.

\section{Conclusion}

This study provides ample evidence that NAcc DA is involved in social attachment. NAcc DA has been implicated in many, although perhaps not all, aspects of reward learning (Berridge and Robinson, 1998) and is believed to be a major component involved in drug addiction (Self et al., 1998). It has been suggested that the neural pathways implicated in drug addiction evolved to mediate reinforcement produced by natural rewards and are involved in adaptive behavior (Di Chiara, 1995; Wise, 1996; Nesse and Berridge, 1997; Zahm, 2000; Kelley and Berridge, 2002). This study provides support for such hypotheses in that NAcc DA is necessary for the social behavior of the monogamous prairie vole. Prairie voles provide a model to examine the neural mechanisms of pair bonding, a social reward relevant to the strong social bonds formed by humans. DA systems are involved in human social behavior, and DAergic drugs are often used to treat disorders associated with social attachment such as autism and social phobia (Mikkelsen et al., 1981; Schneier et al., 2000; Volkmar, 2001). Additional examination of the neurobiology of social attachment may not only lead to a better understanding of these disorders, but also addictive disorders that likely involve similar neural pathways.

\section{References}

Aragona BJ, Curtis JT, Davidson AJ, Wang ZX, Stephan FK (2002) Behavioral and neurochemical investigation of circadian time-place learning in the rat. J Biol Rhythms 17:330-344.

Berridge KC, Robinson TE (1998) What is the role of dopamine in reward: hedonic impact, reward learning, or incentive salience? Brain Res Brain Res Rev 28:309-369.

Blackburn JR, Phillips AG, Jakubovic A, Fibiger HC (1989) Dopamine and preparatory behavior. II. A neurochemical analysis. Behav Neurosci 103:15-23.

Carter CS, Getz LL (1993) Monogamy and the prairie vole. Sci Am 268:100-106.

Cho MM, DeVries AC, Williams JR, Carter CS (1999) The effects of oxytocin and vasopressin on partner preferences in male and female prairie voles (Microtus ochrogaster). Behav Neurosci 113:1071-1079.

Ciliax BJ, Heilman C, Demchyshyn LL, Pristupa ZB, Ince E, Hersch SM, Niznik HB, Levey AI (1995) The dopamine transporter: immunochemical characterization and localization in brain. J Neurosci 15:1714-1723.

Curtis JT, Liu Y, Wang ZX (2001) Lesions of the vomeronasal organ disrupt mating-induced pair bonding in female prairie voles (Microtus ochrogaster). Brain Res 901:167-174.

Curtis JT, Stowe JR, Wang ZX (2003) Differential effects of intraspecific interactions on the striatal dopamine system in social and non-social voles. Neuroscience, in press.

DeVries AC, DeVries MB, Taymans S, Carter CS (1995) Modulation of pair bonding in female prairie voles (Microtus ochrogaster) by corticosterone. Proc Natl Acad Sci USA 92:7744-7748.
DeVries AC, DeVries MB, Taymans SE, Carter CS (1996) The effects of stress on social preferences are sexually dimorphic in prairie voles. Proc Natl Acad Sci USA 93:11980-11984.

Dewsbury DA (1987) The comparative psychology of monogamy. Nebr Symp Motiv 35:1-50.

Di Chiara G (1995) The role of dopamine in drug abuse viewed from the perspective of its role in motivation. Drug Alcohol Depend 38:95-137.

Di Chiara G (1999) Drug addiction as dopamine-dependent associative learning disorder. Eur J Pharmacol 375:13-30.

Freed C, Revay R, Vaughan RA, Kriek E, Grant S, Uhl GR, Kuhar MJ (1995) Dopamine transporter immunoreactivity in rat brain. J Comp Neurol 359:340-349.

Getz LL, Carter CS (1996) Prairie-vole partnerships. Am Sci 84:56-62.

Getz LL, Hofmann JE (1986) Social organization in free-living prairie voles, Microtus ochrogaster. Behav Ecol Sociobiol 18:275-282.

Gingrich B, Liu Y, Cascio C, Wang ZX, Insel TR (2000) Dopamine D2 receptors in the nucleus accumbens are important for social attachment in female prairie voles (Microtus ochrogaster). Behav Neurosci 114:173-183.

Hokfelt T, Martensson R, Bjorklund A, Kleinau S, Goldstein M (1984) Distributional maps of tyrosine-hydroxylase-immunoreactive neurons in the rat brain. In: Handbook of chemical neuroanatomy (Bjorklund A, Hokfelt T, eds), pp 277-379. Amsterdam: Elsevier.

Hull EM, Eaton RC, Markowski VP, Moses J, Lumley LA, Loucks JA (1992) Opposite influence of medial preoptic D1 and D2 receptors on genital reflexes: implications for copulation. Life Sci 51:1705-1713.

Ikemoto S, Panksepp J (1999) The role of nucleus accumbens dopamine in motivated behavior: a unifying interpretation with special reference to reward-seeking. Brain Res Brain Res Rev 31:6-41.

Insel TR, Hulihan TJ (1995) A gender-specific mechanism for pair bonding: oxytocin and partner-preference formation in monogamous voles. Behav Neurosci 109:782-789.

Insel TR, Shapiro LE (1992) Oxytocin receptor distribution reflects social organization in monogamous and polygamous voles. Proc Natl Acad Sci USA 89:5981-5985.

Insel TR, Young LJ (2001) The neurobiology of attachment. Nat Rev Neurosci 2:129-136.

Insel TR, Wang ZX, Ferris CF (1994) Patterns of brain vasopressin receptor distribution associated with social organization in microtine rodents. J Neurosci 14:5381-5392.

Insel TR, Preston S, Winslow JT (1995) Mating in the monogamous male: behavioral consequences. Physiol Behav 57:615-627.

Jansson A, Goldstein M, Tinner B, Zoli M, Meador-Woodruff JH, Lew JY, Levey AI, Watson S, Agnati LF, Fuxe K (1999) On the distribution patterns of D1, D2, tyrosine hydroxylase and dopamine transporter immunoreactivities in the ventral striatum of the rat. Neuroscience 89:473-489.

Kelley AE, Berridge KC (2002) The neuroscience of natural rewards: relevance to addictive drugs. J Neurosci 22:3306-3311.

Lim MM, Young LJ (2002) Blockade of vasopressin Vla receptors in the ventral pallidum prevents partner-preference formation in monogamous male prairie voles. Soc Neurosci Abstr 28:89.2.

Liu Y, Wang ZX (2002) Both dopamine and oxytocin receptors are required for partner-preference formation in female prairie voles. Soc Neurosci Abstr 28:90.2.

Liu Y, Curtis JT, Wang ZX (2001) Vasopressin in the lateral septum regulates pair bond formation in male prairie voles (Microtus ochrogaster). Behav Neurosci 115:910-919.

Mas M, Fumero B, Gonzalez-Mora JL (1995) Voltammetric and microdialysis monitoring of brain monoamine neurotransmitter release during sociosexual interactions. Behav Brain Res 71:69-79.

McGuire B, Novak M (1984) A comparison of maternal behaviour in the meadow vole (Microtus pennsylvanicus), prairie vole (M. ochrogaster) and pine vole (M. pinetorum). Anim Behav 32:1132-1141.

Mikkelsen EJ, Detlor J, Cohen DJ (1981) School avoidance and social phobia triggered by haloperidol in patients with Tourette's disorder. Am J Psychiatry 138:1572-1576.

Missale C, Nash SR, Robinson SW, Jaber M, Caron MG (1998) Dopamine receptors: from structure to function. Physiol Rev 78:189-225.

Nesse RM, Berridge KC (1997) Psychoactive drug use in evolutionary perspective. Science 278:63-66.

Nirenberg MJ, Chan J, Pohorille A, Vaughan RA, Uhl GR, Kuhar MJ, Pickel VM (1997) The dopamine transporter: comparative ultrastructure of 
dopaminergic axons in limbic and motor compartments of the nucleus accumbens. J Neurosci 17:6899-6907.

Nobrega JN, Gernert M, Loscher W, Raymond R, Belej T, Richter A (1999) Tyrosine hydroxylase immunoreactivity and $\left[{ }^{3} \mathrm{H}\right] \mathrm{WIN} 35,428$ binding to the dopamine transporter in a hamster model of idiopathic paroxysmal dystonia. Neuroscience 92:211-217.

Oliveras D, Novak M (1986) A comparison of paternal behaviour in the meadow vole Microtus pennsylvanicus, the pine vole M. pinetorum and the prairie vole M. ochrogaster. Anim Behav 34:519-526.

Paxinos G, Watson C (1986) The rat brain in stereotaxic coordinates, Ed 2. San Diego: Academic.

Pfaus JG, Damsma G, Nomikos GG, Wenkstern DG, Blaha CD, Phillips AG, Fibiger HC (1990) Sexual behavior enhances central dopamine transmission in the male rat. Brain Res 530:345-348.

Pitkow LJ, Sharer CA, Ren X, Insel TR, Terwilliger EF, Young LJ (2001) Facilitation of affiliation and pair-bond formation by vasopressin receptor gene transfer into the ventral forebrain of a monogamous vole. J Neurosci 21:7392-7396.

Radhakishun FS, Van Ree JM (1987) The hypomotility elicited by small doses of apomorphine seems exclusively mediated by dopaminergic systems in the nucleus accumbens. Eur J Pharmacol 137:41-47.

Robbins TW, Everitt BJ (1996) Neurobehavioural mechanisms of reward and motivation. Curr Opin Neurobiol 6:228-236.

Salamone JD, Steinpreis RE, McCullough LD, Smith P, Grebel D, Mahan K (1991) Haloperidol and nucleus accumbens dopamine depletion suppress lever pressing for food but increase free food consumption in a novel food choice procedure. Psychopharmacology 104:515-521.

Schneier FR, Liebowitz MR, Abi-Dargham A, Zea-Ponce Y, Lin SH, Laruelle M (2000) Low dopamine $\mathrm{D}(2)$ receptor binding potential in social phobia. Am J Psychiatry 157:457-459.

SelfDW, Barnhart WJ, Lehman DA, Nestler EJ (1996) Opposite modulation of cocaine-seeking behavior by D1- and D2-like dopamine receptor agonists. Science 271:1586-1589.

Self DW, Genova LM, Hope BT, Barnhart WJ, Spencer JJ, Nestler EJ (1998) Involvement of cAMP-dependent protein kinase in the nucleus accumbens in cocaine self-administration and relapse of cocaine-seeking behavior. J Neurosci 18:1848-1859.

Shippenberg TS, Bals-Kubik R, Herz A (1993) Examination of the neurochemical substrates mediating the motivational effects of opioids: role of the mesolimbic dopamine system and D-1 vs. D-2 dopamine receptors. J Pharmacol Exp Ther 265:53-59.

Smith MT, Pencea V, Wang ZX, Luskin MB, Insel TR (2001) Increased number of BrdU-labeled neurons in the rostral migratory stream of the estrous prairie vole. Horm Behav 39:11-21.

Van Ree JM, Wolterink G (1981) Injection of low doses of apomorphine into the nucleus accumbens of rats reduces locomotor activity. Eur J Pharmacol 72:107-111.

Volkmar FR (2001) Pharmacological interventions in autism: theoretical and practical issues. J Clin Child Psychol 30:80-87.

Voorn P, Jorritsma-Byham B, Van Dijk C, Buijs RM (1986) The dopaminergic innervation of the ventral striatum in the rat: a light- and electronmicroscopical study with antibodies against dopamine. J Comp Neurol 251:84-99.

Wang Y, Lavond DG, Chambers KC (1997) The effects of cooling the area postrema of male rats on conditioned taste aversions induced by $\mathrm{LiCl}$ and apomorphine. Behav Brain Res 82:149-158.

Wang ZX, Yu G, Cascio C, Liu Y, Gingrich B, Insel TR (1999) Dopamine D2 receptor-mediated regulation of partner preferences in female prairie voles (Microtus ochrogaster): a mechanism for pair bonding? Behav Neurosci 113:602-611.

Williams JR, Catania KC, Carter CS (1992) Development of partner preferences in female prairie voles (Microtus ochrogaster): the role of social and sexual experience. Horm Behav 26:339-349.

Williams JR, Insel TR, Harbaugh CR, Carter CS (1994) Oxytocin administered centrally facilitates formation of a partner preference in female prairie voles (Microtus ochrogaster). J Neuroendocrinol 6:247-250.

Winslow JT, Hastings N, Carter CS, Harbaugh CR, Insel TR (1993) A role for central vasopressin in pair bonding in monogamous prairie voles. Nature 365:545-548.

Wise RA (1996) Neurobiology of addiction. Curr Opin Neurobiol 6:243-251.

Young LJ, Wang ZX, Insel TR (1998) Neuroendocrine bases of monogamy. Trends Neurosci 21:71-75.

Young LJ, Lim MM, Gingrich B, Insel TR (2001) Cellular mechanisms of social attachment. Horm Behav 40:133-138.

Zahm DS (2000) An integrative neuroanatomical perspective on some subcortical substrates of adaptive responding with emphasis on the nucleus accumbens. Neurosci Biobehav Rev 24:85-105. 